\title{
Integral Riemann-Stieltjes Pada Fungsi Bernilai Real
}

\author{
Septian Mosal Pirade ${ }^{1}$, Tohap Manurung ${ }^{2}$, Jullia Titaley ${ }^{3 *}$ \\ ${ }^{1,2,3}$ Program Studi Matematika, Fakultas Matematika dan Ilmu Pengetahuan Alam, \\ Universitas Sam Ratulangi Manado \\ *corresponding author email: july_titaley@yahoo.com
}

\begin{abstract}
Abstrak
Integral Riemann-Stieltjes merupakan generalisasi dari Integral Riemann, kedua Integral ini memiliki hubungan, juga beberapa sifat dasar pada Integral Riemann dapat diberlakukan pada Integral RiemannStieltjes. Misalkan $f$ dan $\alpha$ adalah fungsi bernilai real yang terbatas pada interval $[a, b]$. Jika $f \epsilon R[a, b]$ dan $f \epsilon$ $R \alpha[a, b]$, maka sifat terbatas, monoton naik, linear penjumlahan dan linear perkalian terhadap konstanta yang berlaku pada fungsi $f$ yang terintegral Riemann, berlaku juga pada fungsi $f$ yang terintegral Riemann-Stieltjes. Jika $\alpha(x)=x$, maka integral Riemann-Stieltjes ekuivalen dengan integral Riemann, dan dapat direduksi menjadi integral Riemann ketika $\alpha$ mempunyai turunan dan terbatas pada interval terbuka $(a, b)$.
\end{abstract}

Kata kunci : Fungsi Bernilai Real, Integral Riemann, Integral Riemann-Stieltjes.

\section{The Riemann-Stieltjes Integral for Real Function}

\begin{abstract}
The Riemann-Stieltjes Integral is a generalization of the Riemann Integral, both of these integral have a relation, and some basic properties of the Riemann Integral can also be applied to the Riemann-Stieltjes Integral. Let $f$ and $\alpha$ is a real-value function and bounded on interval $[a, b]$. If $f \in R[a, b]$ and $f \in R_{\alpha}[a, b]$, then the elementary integral properties, including bounded variation, monotonically increasing, summation of linear and multipled by constants-value of linear that applies to function $f$ that is Riemann integrable, as well applies to function $f$ that is Riemann-Stieltjes integrable. If $\alpha(x)=x$, then The Riemann-Stieltjes Integral equivalent to The Riemann Integral, and can be reduced to The Riemann Integral when $\alpha$ has a derivative and bounded to the open interval $(a, b)$.
\end{abstract}

Keywords: Real Function, Riemann Integral, Riemann-Stieltjes Integral.

\section{Pendahuluan}

Integral adalah suatu konsep penting dalam Matematika yang dikemukakan pertama kali oleh Isac Newton dan Gottfried Wilhelm Leibniz pada akhir abad ke-17. Konsep integral sering digunakan untuk menentukan luas daerah di bawah kurva dan mencari penyelesaian dari suatu model matematika [1]. Pada tahun 1850, konsep ini diteliti secara lebih mendalam oleh Benrhard Riemann. Riemann mendefinisikan integral suatu fungsi pada domain berupa interval tertutup dan terbatas pada $\mathrm{R}$ sebagai luas daerah di bawah kurva dari fungsi tersebut.

Selanjutnya dikembangkan suatu teori pengintegralan lainnya yang merupakan generalisasi dari konsep integral Riemann, yakni integral Riemann-Stieltjes yang dikemukakan oleh Thomas Joannes Stieltjes pada tahun 1856-1894. Pada integral Riemann-Stieltjes selalu melibatkan dua fungsi, yaitu fungsi bernilai real $f$ yang terdefinisi pada interval $[a, b]$ dan fungsi $\alpha:[a, b] \rightarrow R$ yang merupakan integrator dari fungsi $f$ dimana integrator ini adalah suatu fungsi yang monoton naik pada interval $[a, b][2]$.

\section{Sistem Bilangan Real}

\subsection{Sifat-Sifat Operasi pada Bilangan Real}

Sifat-sifat operasi pada bilangan real antara lain tertutup, komutatif, assosiatif, distributiv, memiliki ivers dan elemen identitas [3] . 


\subsection{Sifat Urutan Bilangan Real}

\subsubsection{Pertidaksamaan}

Menyelesaikan suatu pertidaksamaan adalah mencari semua himpunan bilangan real yang membuat pertidaksamaan tersebut menjadi suatu pernyataan yang benar. Berbeda dengan persamaan yang himpunan penyelesaiannya umumnya terdiri dari satu bilangan atau mungkin sejumlah berhingga bilangan saja, himpunan penyelesaian suatu pertidaksamaan biasanya terdiri dar suatu keseluruhan interval bilangan atau dalam beberapa kasus gabungan dari interval-interval yang demikian [3] .

\subsubsection{Nilai Mutlak}

Secara matematis pengertian harga mutlak dari setiap bilangan real $x$ yang dinotasikan dengan $|x|$, ialah nilai positif dari nilai $x$ dan $-x$. $|x|$ berharga $x$ untuk $x>0$, -x untuk $x<0$ dan 0 untuk $x=0[3]$

\subsection{Sifat Kelengkapan Bilangan Real}

\section{Definisi 1 [1]}

Diberikan $H$ merupakan himpunan bagian dari $\mathcal{R}$.

(i) Sebuah bilangan $u \in \mathcal{R}$ dikatakan merupakan batas atas $H$ apabila $x \leq u$ untuk semua $x \in H$.

(ii) Sebuah bilangan $v \in \mathcal{R}$ dikatakan merupakan batas bawah $H$ apabila $v \leq x$ untuk semua $x \in H$.

\section{Definisi 2 [1]}

(i) Jika $H$ terbatas di atas, maka suatu batas atas $H$, misal saja $u$ dikatakan merupakan supremum (batas atas terkecil) $H$ apabila tidak ada batas atas $H$ yang lain yang kurang dari $u$.

(ii) Jika $H$ terbatas di bawah, maka suatu batas bawah $H$, misal saja $w$ dikatakan merupakan infimum (batas bawah terbesar) $H$, apabila tidak ada batas bawah $H$ lain yang lebih dari $w$.

\subsection{Fungsi}

Jika $a \in A$, maka anggota himpunan $B$ yang merupakan kaitan dari $a$ dapat kita tulis sebagai $f(a)$. Elemen $f(a)$ tersebut dinamakan nilai fungsi dari $a$, atau petaan dari $a$. Himpunan semua petaan disebut range (daerah nilai) dari fungsi $f$. range merupakan himpunan bagian dari codomain. Misalnya $f$ adalah fungsi $f: \mathcal{R} \rightarrow \mathcal{R}, \mathcal{R}$ adalah himpunan bilangan real yang memetakan setiap $x \in \mathcal{R}$ ke kuadratnya [1] .

$$
Y=f(x)=x^{2} \text { atau dapat ditulis pula sebagai } x \rightarrow x^{2}
$$

dalam penulisan di atas, $x$ disebut variabel bebas dan $y$ disebut variabel bergantung. Nilai $y$ bergantung dari pengambilan nilai $x[\mathbf{1}]$.

\subsection{Kontinuitas Fungsi}

Definisi 3 [4]

Misalkan $f$ terdefinisi pada suatu interval terbuka yang mengandung $c$. Maka dapat dikatakan bahwa $f$ kontinu di $c$ jika :

$$
\lim _{x \rightarrow c} f(x)=f(c)
$$

dengan syarat :
a. $\lim _{x \rightarrow c} f(x)$ ada.
b. $f(c)$ ada (yakni, $c$ berada dalam daerah asal $f$ ), dan
c. $\lim _{x \rightarrow(x)}=f(c)$.

jika salah satu dari ketiga syarat ini tak terpenuhi, maka $f$ diskontinu di $c$. 


\section{Integral}

Integral merupakan antiturunan, sehingga jika terdapat fungsi $F(x)$ yang kontinu pada interval $[a, b]$ diperoleh $\frac{d(F(x))}{d x}=F^{\prime}(x)=f(x)$ [5]. Antiturunan dari $f(x)$ adalah mencari fungsi yang turunannya adalah $f(x)$, ditulis $\int f(x) \mathrm{d} x$. Secara umum dapat kita tuliskan :

$$
\int f(x) d x=\int F^{\prime}(x) d x=F(x)+C
$$

\section{Partisi dan Jumlah Riemann}

\subsection{Partisi}

Sebuah fungsi $f$ didefinisikan pada interval tertutup $[a, b]$. Fungsi ini bisa bernilai positif ataupun negatif pada interval tersebut dan bahkan tidak perlu kontinu. Misalkan suatu partisi $P$ membagi interval $[a, b]$ menjadi $n$ sub-interval (tidak perlu sama panjang) dengan menggunakan titik-titik $a=x_{0}<x_{1}<x_{2}<\ldots<x_{n-1}<x_{n}=b$. Dengan jarak tiap sub-interval adalah $\left[x_{0}, x_{1}\right],\left[x_{1}, x_{2}\right], \cdots,\left[x_{n-1}, x_{n}\right]$. Panjang sub-interval tersebut dapat dilambangkan $\Delta x_{1}, \Delta x_{2}, \cdots, \Delta x_{n}$. Maka, jika $1 \leq i \leq n$, maka $\Delta x_{i}=x_{i}-x_{i-1}[4]$.

\subsection{Jumlah Riemann}

\section{Definisi 4 [4]}

Diberikan fungsi terbatas $f:[a, b] \rightarrow \mathcal{R}$ dan partisi $P=\left\{x_{0}, x_{1}, x_{2}, \ldots, x_{n-1}, x_{n}\right\}$

pada $[a, b]$. Jumlah Riemann atas dan jumlah Riemann bawah dari fungsi $f$ sehubungan dengan partisi $P$ didefinisikan dengan :

$$
\begin{aligned}
& U(f ; P)=\sum_{i=1}^{n} M_{i} \Delta x_{i}=\sum_{i=1}^{n} M_{i}\left(x_{i}-x_{i-1}\right) \\
& L(f ; P)=\sum_{i=1}^{n} m_{i} \Delta x_{i}=\sum_{i=1}^{n} m_{i}\left(x_{i}-x_{i-1}\right)
\end{aligned}
$$

Pada setiap sub-interval $\left[x_{i-1}, x_{i}\right]$ kita ambil sebuah titik sebarang $w_{i}$ (yang mungkin saja sebuah titik ujung), kita sebut itu sebagai titik sampel untuk sub-interval ke-i.

Partisi yang terbentuk merupakan segiempat dengan ukuran $\Delta x$ dan $f\left(w_{i}\right)$ sebagai panjang dan lebarnya, sehingga luas tiap partisi adalah $f\left(w_{i}\right) \Delta x$. Karena itu didapatkan jumlah luas partisi pada selang [a,b] yaitu $\sum_{i=1}^{n} f\left(w_{i}\right) \Delta x$, yang disebut dengan Jumlah Riemann [6] .

$$
S(f ; P)=\sum_{i=1}^{n} w_{i} \Delta x_{i}=\sum_{i=1}^{n} w_{i}\left(x_{i}-x_{i-1}\right)
$$

\section{Integral Darboux}

\subsection{Jumlah Darboux Atas dan Jumlah Darboux Bawah} Lemma 1 [7]

Diberikan $[a, b] \subseteq \mathcal{R}$, jika $f:[a, b] \rightarrow \mathcal{R}$ fungsi yang terbatas pada $[a, b]$ dan $P=\left\{a=x_{0}, x_{1}, x_{2}, \ldots, x_{n}=b ; \xi_{1}, \xi_{2}, \cdots, \xi_{n}\right\}$ sembarang partisi pada $[a, b]$, maka berlaku :

\section{Teorema $1[7]$}

$$
L(f ; P) \leq U(f ; P)
$$

Diberikan $[a, b] \subseteq \mathcal{R}$, jika $f:[a, b] \rightarrow \mathcal{R}$ fungsi yang terbatas pada $[a, b]$. Jika $P_{1}$ dan $P_{2}$ sebarang partisi pada $[a, b]$ dengan $P_{1} \subseteq P_{2}$, maka berlaku :

$$
L\left(f ; P_{1}\right) \leq U\left(f ; P_{2}\right)
$$

\subsection{Integral Darboux Atas dan Integral Darboux Bawah}

\section{Teorema 2 [7]}

Diberikan $[a, b] \subseteq \mathcal{R}$, jika $f:[a, b] \rightarrow \mathcal{R}$ fungsi yang terbatas pada $[a, b]$. Jika fungsi $f$ terintegral

Darboux Atas dan Darboux Bawah pada interval $[a, b]$, maka:

$$
L(f) \leq U(f)
$$

Karena $f$ juga terintegral Riemann, maka Teorema ini juga berlaku untuk Integral Riemann. 


\section{Integral Riemann}

\section{Definisi 5 [4]}

$f$ adalah fungsi bilangan real pada interval tertutup $[a, b]$ dan $R=R[a, b]$ adalah himpunan dari keseluruhan partisi dari $[a, b]$, maka integral riemann atas dan integral riemann bawah didefinisikan sebagai berikut :

$$
\int_{a}^{\bar{b}} f(x) d x=\inf U(f ; P), P \in R \quad \text { dan } \quad \int_{\underline{a}}^{b} f(x) d x=\sup L(f ; P), P \in R
$$

Jika $\int_{a}^{\bar{b}} f(x) d x=\int_{a}^{b} f(x) d x$, maka fungsi $f$ dikatakan terintegral riemann dan dinotasikan :

$$
S(f)=\int_{a}^{b} f(x) d x
$$

\section{Teorema 3 [8]}

Diketahui fungsi $f \in R[a, b]$ terbatas. Fungsi $f$ terintegral Riemann pada $[a, b]$ jika dan hanya jika untuk setiap bilangan $\varepsilon>0$ terdapat bilangan $\delta>0$ sehingga jika $P_{1}$ dan $P_{2}$ partisi pada $[a, b]$ dengan $\left\|P_{1}\right\|<\delta$ dan $\left\|P_{2}\right\|<\delta$ berakibat :

$$
U(f ; P)-L(f ; P)<\varepsilon
$$

Teorema 4 [9]

Jika $f$ terintegral Riemann pada $[a, b]$, maka fungsi $f$ terbatas pada $[a, b]$.

Teorema 5 [9]

Jika $f$ terintegral Riemann pada $[a, b]$, maka nilai integralnya tunggal.

Teorema 2.10 (Linear - Penjumlahan) [9]

Jika $f, g \in R[a, b]$ dan $(f+g) \in R[a, b]$, maka :

$$
\int_{a}^{b}(f+g)(x) d x=\int_{a}^{b} f(x) d x+\int_{a}^{b} g(x) d x
$$

Teorema 6 (Linear - Perkalian terhadap Konstanta) [9]

Jika $f, g \in R[a, b]$ dan $c f \in R[a, b]$, maka :

$$
\int_{a}^{b} c f(x) d x=c \int_{a}^{b} f(x) d x
$$

\section{Metodologi Penelitian}

Metode yang digunakan adalah metode literatur. Dengan langkah-langkah penelitian sebagai berikut :

a) Mencari tahu kriteria pengintegralan Riemann-Stieltjes.

b) Mempelajari sifat-sifat dasar Integral Riemann-Stieltjes.

c) Menemukan hubungan antara Integral Riemann Integral Riemann-Stieltjes.

d) Memberikan contoh soal fungsi yang terintegral Riemann-Stieltjes dan fungsi yang tidak terintegral Riemann-Stieltjes.

\section{Hasil dan Pembahasan}

\subsection{Jumlah Riemann-Stieltjes Atas dan Riemann-Stieltjes Bawah Definisi 5}

$f$ adalah fungsi bilangan real pada interval tertutup $I=[a, b]$ dan $\alpha$ adalah suatu fungsi monoton naik yang terdefinisi pada interval $I$ dengan $P$ merupakan partisinya, jika :

$$
M_{i}=\sup \left\{f(x): x \in\left[x_{i-1}, x_{i}\right]\right\}, \quad \text { dan } \quad m_{i}=\inf \left\{f(x): x \in\left[x_{i-1}, x_{i}\right]\right\}
$$

Selanjutnya Jumlah Riemann-Stieltjes Atas dan Jumlah Riemann-Stieltjes Bawah fungsi $f$ terhadap $\alpha$ terkait dengan partisi $P$, dinyatakan dengan :

$$
U(f, \alpha ; P)=\sum_{i=1}^{n} M_{i}\left(\alpha\left(x_{i}\right)-\alpha\left(x_{i-1}\right)\right), \text { dan }
$$




$$
L(f, \alpha ; P)=\sum_{i=1}^{n} m_{i}\left(\alpha\left(x_{i}\right)-\alpha\left(x_{i-1}\right)\right)
$$

\section{Lemma 2}

Diberikan $f$ adalah suatu fungsi yang terbatas dan terdefinisi pada $[a, b]$ dan $\alpha$ adalah fungsi yang monoton naik pada $[a, b] . P=\left\{a=x_{0}, x_{1}, x_{2}, \ldots, x_{n}=b\right\}$ merupakan sebarang partisi pada $[a, b]$, maka berlaku :

$$
L(f, \alpha ; P) \leq U(f, \alpha ; P)
$$

\section{Teorema 7}

Misalkan $f$ adalah suatu fungsi yang terbatas dan terdefinisi pada $[a, b]$ dan $\alpha$ adalah fungsi yang monoton naik pada $[a, b]$. Jika $P_{1}$ dan $P_{2}$ sebarang partisi pada $[a, b]$ dengan $P_{1} \subseteq P_{2}$, maka berlaku:

$$
L\left(f, \alpha ; P_{1}\right) \leq U\left(f, \alpha ; P_{2}\right)
$$

\subsection{Integral Riemann-Stieltjes}

\section{Definisi 6}

$f$ adalah fungsi kontinu dari bilangan real yang terbatas pada interval tertutup $I=[a, b]$ dan $\alpha$ adalah suatu fungsi monoton naik yang terdefinisi pada interval $I$ dengan $P$ merupakan partisinya. Maka integral Riemann-Stieltjes Atas dan integral Riemann-Stieltjes Bawah didefinisikan sebagai berikut :

\section{Teorema 8}

$$
\begin{gathered}
U(f, \alpha)=\int_{a}^{\bar{b}} f d \alpha=\inf \left\{U(f, \alpha ; P): P \in R_{\alpha}[a, b]\right\} \text { dan } \\
L(f, \alpha)=\int_{\underline{a}}^{b} f d \alpha=\sup \left\{L(f, \alpha ; P): P \in R_{\alpha}[a, b]\right\}
\end{gathered}
$$

Misalkan $f$ adalah suatu fungsi yang terbatas dan terdefinisi pada $[a, b]$ dan $\alpha$ adalah fungsi yang monoton naik pada $[a, b]$. Jika fungsi $f$ terintegral Riemann-Stieltjes Atas dan Riemann-Stieltjes Bawah pada interval $[a, b]$, maka:

$$
\int_{\underline{a}}^{b} f d \alpha \leq \int_{a}^{\bar{b}} f d \alpha
$$

\section{Definisi 7}

Diberikan $f$ fungsi bilangan real yang terbatas pada interval tertutup $I=[a, b]$ dan $\alpha$ adalah suatu fungsi monoton naik yang terdefinisi pada interval I. Jika $\int_{a}^{\bar{b}} f d \alpha=\int_{\underline{a}}^{b} f d \alpha$, maka fungsi $f$ dikatakan terintegral Riemann-Stieltjes dan dinotasikan dengan :

$$
\int_{a}^{b} f d \alpha
$$

\section{Teorema 9 (Kriteria Pengintegralan Riemann-Stieltjes)}

Diketahui fungsi $f \in R_{\alpha}[a, b]$ terbatas dan $\alpha$ adalah suatu fungsi monoton naik yang terdefinisi pada interval $I$. Fungsi $f$ terintegral Riemann-Stieltjes pada $[a, b]$ jika dan hanya jika untuk setiap bilangan $\varepsilon>0$ terdapat bilangan $\delta>0$ dan ada partisi $P$ yang membagi $[a, b]$ sedemikian sehingga :

$$
U(f, \alpha ; P)-L(f, \alpha ; P)<\varepsilon
$$

\subsection{Sifat Dasar Integral Riemann-Stieltjes}

Ada beberapa teorema dasar yang menjamin bahwa fungsi bernilai real yang memiliki sifat tertentu akan terintegral Riemann-Stieltjes, sifat yang akan dibahas di dalam skripsi ini diantaranya ialah sifat kontinu, monoton naik dan kelinearan fungsi integral Riemann-Stieltjes.

\section{Teorema 10}

Jika $f$ kontinu pada $[a, b]$ dan $\alpha$ monoton naik pada $[a, b]$, maka $f$ terintegral Riemann-Stieltjes. 


\section{Teorema 11}

Jika $f$ monoton pada $[a, b]$ dan $\alpha$ kontinu dan monoton naik pada $[a, b]$, maka $f$ terintegral Riemann-Stieltjes.

Teorema 12 (Linear - Penjumlahan)

Jika $f, g \in R_{\alpha}[a, b]$ dan $f+g \in R_{\alpha}[a, b]$, maka :

$$
\int_{a}^{b}(f+g) d \alpha=\int_{a}^{b} f d \alpha+\int_{a}^{b} g d \alpha
$$

Teorema 13 (Linear - Perkalian terhadap Konstanta)

Jika $f \in R_{\alpha}[a, b]$ dan $c f \in R_{\alpha}[a, b]$ untuk c sebarang nilai konstan, maka berlaku:

$$
\int_{a}^{b} c f d \alpha=c \int_{a}^{b} f d \alpha
$$

\section{Teorema 14}

Jika $f \in R_{\alpha}[a, b]$ dimana $c$ adalah bilangan konstan dan $f \in R_{(c \alpha)}[a, b]$, maka :

$$
\int_{a}^{b} f d(c \alpha)=c \int_{a}^{b} f d \alpha
$$

\subsection{Hubungan Antara Integral Riemann dan Integral Riemann-Stieltjes}

\section{Teorema 15}

Sebelumnya telah diketahui bahwa Integral Riemann-Stieltjes memiliki sifat monoton naik, sekarang akan ditunjukkan bahwa Integral Riemaan juga mempunya sifat yang sama, yaitu monoton naik. Jika $f$ monoton pada $[a, b]$, maka $f$ terintegral Riemann.

Jika $f \in R[a, b]$ dan $f \in R_{\alpha}[a, b]$, dimana $\alpha(x) \neq$ konstan dan $\alpha(a) \neq \alpha(b)$, maka :

- Sifat Monoton naik $f$ pada Teorema 4.10 juga merupakan sifat bagi $\alpha$ pada Teorema 4.5.

- Sifat Linier $f$ pada Teorema 4.6 dan Teorema 4.7 juga merupakan sifat bagi $\alpha$ pada Teorema 4.6 dan Teorema 4.7.

\section{Teorema 16}

Asumsikan $\alpha$ adalah fungsi monoton naik dan $\alpha^{\prime} \in R$ pada selang $[a, b]$. Misalkan $f$ adalah fungsi bernilai real yang terbatas pada selang $[a, b]$. maka $f \in R_{\alpha}[a, b]$ jika hanya jika $f \alpha^{\prime} \in R[a, b]$. Atau dalam kasus ini :

$$
\int_{a}^{b} f d \alpha=\int_{a}^{b} f(x) \alpha^{\prime}(x) d x
$$

\subsection{Contoh Fungsi yang Terintegral Riemann-Stieltjes Dan yang Tidak Terintegral Riemann-Stieltjes}

\section{Contoh 1. (Fungsi yang tidak terintegral Riemann-Stieltjes)}

Fungsi $(x)=\left\{\begin{array}{cc}1, & x \in \mathcal{Q} \\ 0, & x \in \mathcal{R}-\mathcal{Q}\end{array}\right.$. Dan $\alpha$ adalah fungsi yang monoton naik pada $[a, b]$, akan ditunjukkan bahwa $f$ tidak terintegral Riemann-Stieltjes terhadap $\alpha$.

\section{Contoh 2. (Fungsi yang terintegral Riemann-Stieltjes)}

Fungsi $(x)=\left\{\begin{array}{cc}1, & x \in \mathcal{Q} \\ 0, & x \in \mathcal{R}-\mathcal{Q}\end{array}\right.$. Dan $\alpha$ adalah fungsi yang monoton naik pada $[a, b]$, dimana $\alpha(x)=$ $r, \forall x \in[a, b]$. Akan ditunjukkan bahwa $f$ terintegral Riemann-Stieltjes terhadap $\alpha$. 


\section{Kesimpulan}

Berdasarkan hasil penelitian dan pembahasan, maka diperoleh kesimpulan sebagai berikut :

a. Sifat-sifat dasar yang berlaku pada Integral Riemann-Stieltjes yaitu sifat kontinu, monoton, linear, semi linear dan keterbatasan fungsi.

b. Pada umumnya sifat-sifat yang berlaku pada integral Riemann, berlaku juga untuk integral Riemann-Stieltjes. Integral Riemann-Stieltjes ekuivalen dengan integral Riemann jika $\alpha(x)=$ $x$, dan dapat direduksi menjadi integral Riemann ketika $\alpha$ mempunyai turunan dan terbatas pada interval terbuka $(a, b)$.

\section{Daftar Pustaka}

[1] Bartle, R. G., and D. R. Sherbert. 2000. Introduction to Real Analysis : Third Edition. John Willey \& Sons, Inc, 605 Third Avenue. New York.

[2] Sari, S. G. 2012. Integral Riemann-Stieltjes Dari Fungsi Bernilai Vektor. Universitas Pendidikan Indonesia.

[3] Jacob, C. 2016. Konstruksi Sistem Bilangan Real. http://file.upi.edu/ Direktori/FPMIPA/JUR._PEND._MATEMATIKA/194507161976031CORNELIS_JACOB/KONSTRUKSI_BIL_REAL.pdf. [ 9 September 2016 ].

[4] Varberg, D., E. J. Purcell, S. E. Rigdon. 2010. Kalkulus Edisi Kesembilan. Terjemahan I Nyoman Susila. Erlangga. Jakarta.

[5] Negoro, S. T., dan B. Harahap. 2005. Ensiklopedia Matematika :Fungsi dan Integral. Ghalia Indonesia.

[6] Reta, W. 2014. Bab-7 Materi Integral Reimann Mata Kuliah Analisis Real 2. https://www.scribd.com/doc/207824374/Bab-7-Integral-Riemann. [ 1 Juni, 2016 ].

[7] Tobirin, dan Herawan. 2011. Integral Darboux. https://yusiriza.files.wordpress.com/2011/10/9.pdf. [ 5 September 2016 ].

[8] Jauhari, M. A., dkk. 2011. Pengantar Analisis Real : Integral Riemann. Fakultas Sains dan Teknologi Universitas Islam Negeri Sunan Kalijaga. Yogyakarta.

[9] Muslich, Sutrima, dan S. Wibowo. 2016. Definisi Integral Riemann Melalui Pendekatan Barisan Fungsi Tangga. Prosiding. 768-775. 